\title{
PERİ-İMPLANT DEFEKTİN TEDAVİSİNDE ALTERNATİF BİR METOD OLARAK BUKKAL YAĞ DOKUNUN KULLANIMI: BİR OLGU RAPORU ${ }^{\neq}$

\author{
THE USE OF THE BUCCAL FAT PAD AS AN ALTERNATIVE METHOD TO REPAIR \\ PERI-IMPLANT DEFECT: A CASE REPORT ${ }^{*}$
} 4

\author{
Doç.Dr. Figen Öngöz DEDE* \\ Doç.Dr. Şeyma Bozkurt DOĞAN**
}

Arş.Gör.Dt. Selman ÇELEN*

Prof.Dr. Varol ÇANAKÇI*

\author{
Makale Kodu/Article code: 3808 \\ Makale Gönderilme tarihi: 13.08 .2018 \\ Kabul Tarihi; 14.02.2019
}

DOI : $10.17567 /$ ataunidfd.527005
Figen Öngöz Dede: ORCID ID: 0000-0002-4211-3359

Selman Çelen: ORCID ID: 0000-0003-2983-8758

Seyma Bozkurt Doğan: ORCID ID: 0000-0001-5670-6430

Varol Çanakçı: ORCID ID: 0000-0002-5314-0889

\section{ÖZ}

Giriş: Peri-implant defektler, dental implant yerleştirilmesinden sonra protetik yükleme yapılmadan hastaya veya cerrahi uygulamalara bağlı nedenlerle oluşabilmektedir. Son zamanlarda bukkal yağ dokunun fibröz iyileşme potansiyeli nedeniyle periimplant defektlerin iyileştirilmesine katkıda bulunduğu ve tatmin edici klinik ataçman seviyesi sağladığı belirtilmiştir. Bu olgu raporunda peri-implant defektin, otojen kemik grefti ve membran olarak bukkal yağ dokusu ile yapılan tedavisi gösterilmektedir. Olgu raporu: 60 yaşındaki erkek hastanın sol alt çene birinci molar bölgesine yerleştirilen implant etrafında klinik ve radyografik muayene esnasında alveoler kemik kaybı ve dișeti inflamasyon varlığı tespit edildi. Öncelikle lokal anestezi altında flep kaldırıldıktan sonra titanyum küretlerle implant çevresindeki granülasyon dokuları uzaklaştırıldı ve $\% 3$ 'lük $\mathrm{H}_{2} \mathrm{O}_{2}$ ile implant yüzeyine muamele yapıldı. İmplant etrafındaki defekt otojen kemik grefti ile dolduruldu ve üzeri bukkal yağ dokudan elde edilen serbest bukkal yağ grefti ile kapatıldı. 2 yıllık takip dönemi boyunca klinik ve radyografik olarak implant ve etrafındaki periodontal dokuların sağlıklı bir şekilde korundukları gözlendi.

Sonuç: Bukkal yağ dokusu, implant etrafındaki defekte doldurulan kemik greft partiküllerini koruyarak yumuşak dokuya kolayca adapte olmuştur. Ancak bukkal yağ dokusunun, peri-implant defektlerin tedavisinde etkisinin değerlendirilebilmesi için in-vivo çalışmalarla desteklenmesine ihtiyaç vardır.

Anahtar Kelimeler: Peri-implant defekt, bukkal yağ dokusu, yumuşak doku grefti

\section{ABSTRACT}

Aim: Peri-implant defects may occur due to reasons related to the patient or surgical applications without prosthetic loading after dental implant placement. Recently, it has been reported that buccal fat pad contributes to the improvement of periimplant defect because of the potential of fibrous healing and provides satisfactory clinical attachment level. In this case report, treatment of peri-implant defect with an autogenous bone graft and buccal fat pad as a barrier membrane is presented.

Case Report: A 60-year-old male patient was determined to have alveolar bone loss and gingival inflammation during clinical and radiographic examination around the implant placed in the first molar region of the left mandible. The periodontal flap was removed under local anesthesia, then the granulation tissue around the implant was removed with titanium curettes and the implant surface was treated with $3 \% \mathrm{H}_{2} \mathrm{O}_{2}$. The defect around the implant was filled with autogenous bone graft and covered with free buccal fat graft from the buccal fat pad. Regarding the clinical and radiological examination, it was observed that the implant and surrounding periodontal tissues were maintained healthy during 2-year follow-up period.

Conclusions: Buccal fat pad, improves the protection of the bone graft particles and is also easily adaptable to soft tissue. However, there is a need to be supported by in-vivo studies to evaluate the effect of the use of buccal fat pad for treatment of peri-implant defects.

Key Words: Peri-implant defect, buccal fat pad, soft tissue graft

*Ordu Üniversitesi, Diş Hekimliği Fakültesi, Periodontoloji AD, Ordu

**Yıldırım Beyazıt Üniversitesi, Diș Hekimliği Fakültesi, Periodontoloji AD, Ankara

${ }^{\ddagger}$ Bu olgu raporu 'Türk Periodontoloji Derneği 47. Uluslararası Bilimsel Kongresi ve 26. Bilimsel Sempozyumu' kapsamında poster olarak sunulmuştur ( 17-18 Kasım 2017, İstanbul, Türkiye).

Kaynakça Bilgisi: Öngöz Dede F, Çelen S, Bozkurt Doğan Ş, Çanakçı V. Peri-İmplant Defektin Tedavisinde Alternatif Bir Metod Olarak Bukkal Yağ Dokunun Kullanımı: Bir Olgu Raporu. Atatürk Üniv Diş Hek Fak Derg 2020; 30: 295-299.

Citation Information: Ongoz Dede F, Celen S, Bozkurt Dogan S, Canakci V. The Use of the Buccal Fat Pad as an Alternative Method to Repair PeriImplant Defect: A Case Report. J Dent Fac Atatürk Uni 2020; 30: 295-299. 


\section{GİRIŞ}

Dişsiz bölgelerin protetik rehabilitasyonu için günümüzde oldukça yaygın uygulanan dental implantlar sonrasında, protetik yükleme yapılmadan hastaya veya cerrahi uygulamaya bağlı nedenlerle implant etrafında osseointegrasyon elde edilmesine rağmen marjinal kemik kaybı ile karşılaşılabilmektedir ${ }^{1}$. Marjinal kemik kaybı, yumuşak doku kaybı ile estetiği etkileyebilir veya cep derinliğindeki artış ileriki dönem anaerobik bakteri varlığı ile peri-implantitise neden olabilir ${ }^{1}$. $\mathrm{Bu}$ nedenle, peri-implant kemik defektlerinin tedavisi uzun dönem implant protez başarısının artırıması bakımından kritik öneme sahiptir ${ }^{1}$. Peri-implant defektlerin tedavisinde, titanyum el aletleri veya ultrasonik aletler ile yapılan mekanik debridmanlar, topikal uygulanan antiseptik/ antimikrobiyal malzemeler, Er: YAG lazer cihazı ve farklı kemik rejeneratif prosedürleri gibi çeşitli tedavi yöntemlerinin kullanıldığı rapor edilmiştir ${ }^{2,3}$. Son dönemde yapılan bir meta-analizde peri-implant defektlerin tedavisinde, cerrahi olmayan yaklaşımlara göre cerrahi prosedürler ile daha iyi sonuçlar elde edildiği rapor edilmiştir ${ }^{2}$.

Bukkal yağ dokusu, buksinatör kas ve masseter kasın anterior kenarı arasında yerleşmiş yuvarlak bir yağ kütlesidir ve ince bir fasya kılıfı ile örtülüdür ${ }^{4}$. Fonksiyon olarak, kaslar arası hareketi artırdığı, bebeklerde emme sırasında yanağın içeri çökmesini önlediği ve yüzün şekline katkıda bulunduğu düşünülmektedir ${ }^{5}$. Oral defektlerin tedavisinde bukkal yağ dokunun kullanımı hakkında çok çeşitli çalışmalar yayınlanmıştır ${ }^{6}$. Bukkal yağ doku, en yaygın oro-antral veya oro-nasal defektlerin kapatılmasında kullanılmıştır ${ }^{7,8}$. Ayrıca, maksiller kist veya tümör rezeksiyonları sonrası $^{9}$, mukozal defektlerin ${ }^{10}$, palatal yarıkların ${ }^{11}$, sinüs ogmentasyonu esnasında sinüs perforasyonunun kapatılmasında bukkal yağ dokusu kullanılmıştır ${ }^{12}$. Son zamanlarda yapılan bir çalışmada, kemik greftini destekleyen bir membran olarak, kemik ogmentasyonu operasyonunda primer yumuşak doku kapanmasını ve kalınlığını artırmak için bukkal yağ dokusundan elde edilen serbest yağ doku grefti (SBYG) kullanıldığı bildirilmiştir ${ }^{13}$.

Serbest yağ doku greftlerinin iyileşmesinin ana mekanizması fibrozisdir. Kablan ve Laster $^{13}$, bukkal yağ greftinin fibröz iyileşmesinden dolayı yapışık dişetini taklit ettiğini ileri sürmüşlerdir. Kablan ${ }^{14}$, serbest bukkal yağ greftinin fibröz iyileşme potansiyeli nedeniyle peri-implant lezyonlarının iyileştirilmesine katkıda bulunduğu ve tatmin edici klinik ataçman seviyesi sağladığını belirtmiştir. Diğer taraftan, Peñarrocha-Diago ve ark. ${ }^{15}$ peri-implant kemik defektlerinin tedavisinde uygulanan kemik greftleri için örtücü materyal olarak bukkal yağ doku kullanımının, hastalar tarafından iyi tolere edildiği ve ileri dönem protetik yükleme sonrasında tatmin edici sonuçlar meydana getirdiğini rapor etmişlerdir.

Yapılan literatür taramasında, yeni ve alternatif bir metod olarak peri-implant defektlerin tedavisinde bariyer membran olarak bukkal yağ dokunun uygulandığı iki çalışmaya rastlanmıştır ${ }^{14,15}$. Bu çalışma verilerinin doğrultusunda, bu olgu raporunda peri-implant defektin otojen kemik grefti ve bariyer membran olarak serbest bukkal yağ grefti (SBYG) ile yapılan cerrahi tedavisi gösterilmektedir.

\section{VAKA RAPORU}

Ordu Üniversitesi Diş Hekimliği Fakültesi Periodontoloji kliniğine başvuran 60 yaşındaki erkek hastanın mandibular sol 1.molar bölgesine yaklaşık bir yıl önce yerleştirilen ve protetik yükleme yapılmamış implantının etrafında klinik ve radyografik muayene esnasında alveoler kemik kaybı ve dişeti inflamasyon varlığı tespit edildi (Resim-1a ve b). Klinik muayenede implant çevresinde $7 \mathrm{~mm}$ sondalanabilir cep derinliği saptandı (Resim-1c).Çalışmamız için Marmara Üniversitesi Sağlık Bilimleri Enstitüsü Girişimsel Olmayan Klinik Araştırmalar Etik Kurulu Komitesi'nden 21.12.2012 tarih ve 10 sayı ile onay alındı. Hastamızdan 'Aydınlatılmış Onam Formu' (Şekil 1) ve fotoğraflar için izin alındıktan sonra ilk seansta defekt bölgesine titanyum küretler yardımı ile mekanik debridman ve sonrasında subgingival irrigasyon işlemleri ile cerrahi olmayan periodontal tedavi uygulandı. Ayrıca, hastamıza oral hijyen eğitimi verildi. Hasta 14 gün sonra tekrar ikinci seansa çağrıldı. Periodontal inflamasyonun iyileştiği tespit edildikten 1 ay sonra, implant etrafın- daki kemik defekt varlığında cerrahi olmayan mekanik tedavinin sınırlı klinik iyileşme sağlaması nedeniyle cerrahi faza geçilmesine karar verildi.

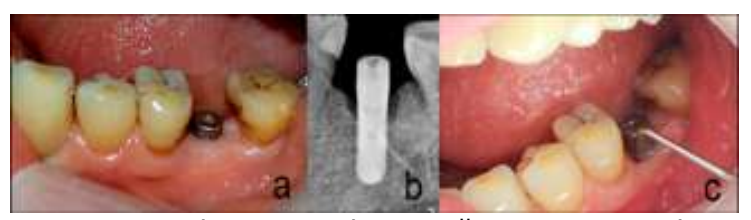

Resim-1: a. Tedavi öncesi olgunun ağız içi görünümü. b. Tedavi öncesi implantın radyografik görünümü c.İmplant çevresindeki defektin periodontal sond ile muayenesi. 
Rasta oscasposse

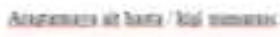

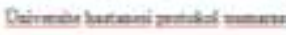

dermast:

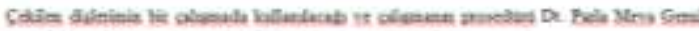

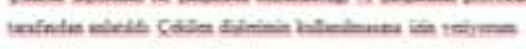

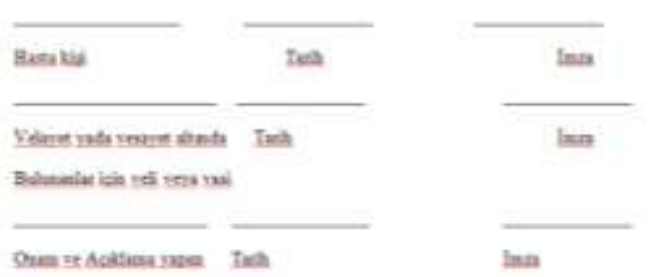

Şekil 1. Aydınlatılmış onam formu

Cerrahi bölgede lokal anestezi sağlandıktan sonra, defekt sınırlarını rahatça görecek şekilde tam kalınlık mukoperiosteal flep kaldırıldı. İmplantın etrafından yüzük şeklinde enfekte yumuşak doku titanyum küretler yardımıyla uzaklaştırıldıktan sonra, implant yüzeyinin dekontaminasyonu için \%3'lük hidrojen peroksit kullanıld ${ }^{16}$. İmplant yüzeyinin yaklaşık $2 \mathrm{dk}^{\prime} \mid \mathrm{lk}$ dekontaminasyonu sonrası implant yüzeyi ve yara bölgesi steril serum fizyolojik ile iyice yıkandı (Resim-2).

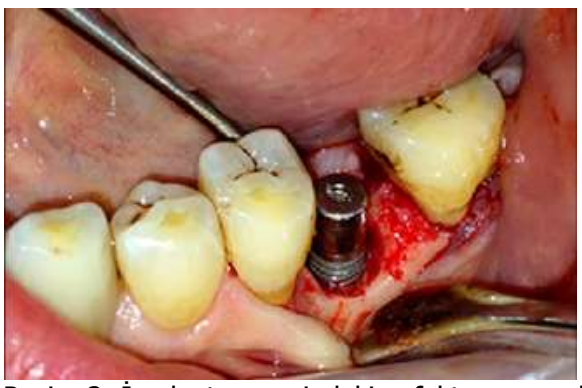

Resim-2: İmplant çevresindeki enfekte yumuşak dokuların temizlenmesi ve \%3'lük $\mathrm{H} 2 \mathrm{O} 2$ ile dekontaminasyonundan sonraki görünüm.

Krater şeklinde kemik defektinin rejenerasyonu için sol posterior mandibuler bukkal bölgeden kemik kazıyıcı yardımı ile otojen kemik grefti toplandı (Resim3a) ve kemik defekt bölgesine yerleştirildi (Resim-3b). Lokal anestezi uygulandıktan sonra maksiller sağ premolar-molar bölgede uygun mukoperiosteal vestibüler flep hazırlandı. Flebin altından, 2. üst molar diş hizasından periosta $1-1.5 \mathrm{~cm}$ uzunluğunda horizontal bir insizyon yapıldı. Buradan eğri dişsiz bir hemostatla yanağa doğru künt diseksiyonla girildi ve bukkal yağ dokusu, yanağın dışından nazikçe elle baskı uygulanıp gerginlik yaratmadan yeterli miktarda defekti kapatabileceğine inanılana kadar çıkarıldı (Resim-4a-b) ve defektin üzerine getirilerek yerleştirildi (Resim-4c).

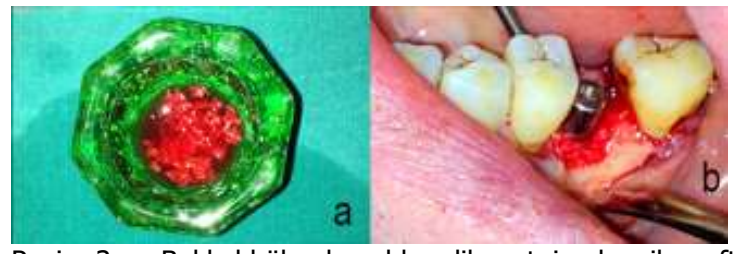

Resim-3: a. Bukkal bölgeden elde edilen otojen kemik grefti, b. İmplant çevresindeki defekte kemik greftinin yerleştirilmesi

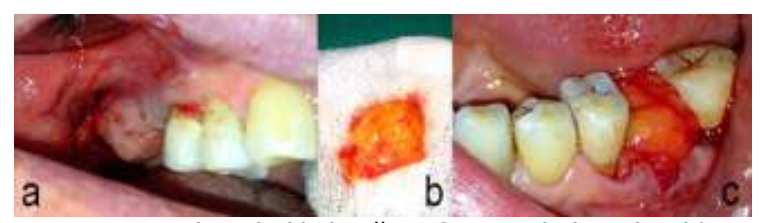

Resim-4: a.Serbest bukkal yağ grefti verici bölge. b. Elde edilen serbest bukkal yağ grefti, c. Serbest bukkal yağ greftinin, defekte konulan kemik greftinin üzerine membran olarak yerleştirilmesi

Periosteal-serbestleştirme insizyonları ile flep mobilizasyonu elde edildikten sonra 3.0 ipek sütur ile SBYG kısmen ağız ortamında açıkta kalacak şekilde yara ağızları dikildi (Resim 5). Hastaya 5 gün için günde iki defa klavulanik asitli $1 \mathrm{gr}$ amoksisilin antibiyotik profilaksisi başlandı. Ayrıca analjezik ve kimyasal plak kontrolü için klorheksidinli glukonat $(\% 0,2)$ gargara verildi. Süturlar cerrahiden 10 gün sonra alındı.

Hastamızda uyguladığımız bu prosedürün postoperatif dönemde kolaylıkla tolere edildiği ve defektlerin komplikasyonsuz kapandığı gözlendi (Resim-6). 2 yıllık takip dönemi boyunca klinik ve radyografik olarak implant ve etrafındaki periodontal dokuların sağlıklı bir şekilde korundukları gözlendi (Resim-7).

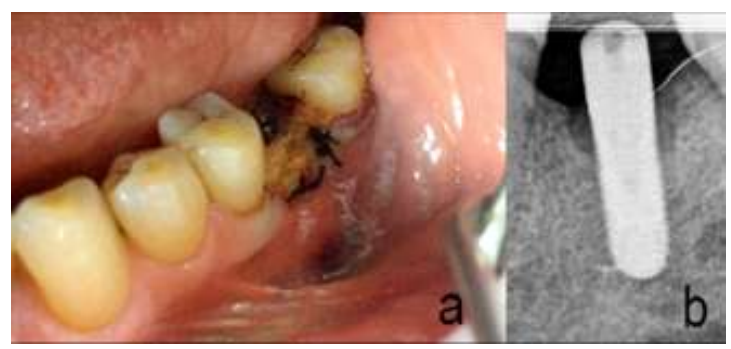

Resim-5: a. Serbest bukkal yağ greftinin kısmen açık kalması ile flebin kapatılması b. Operasyon sonrası radyografik görünüm 


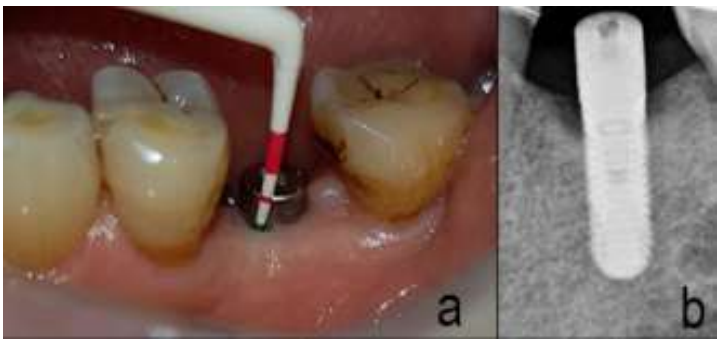

Resim-6: a. Tedavi sonrası 6.ay ağız içi görünümü b. Tedavi sonrası 6.ay radyografik görünüm

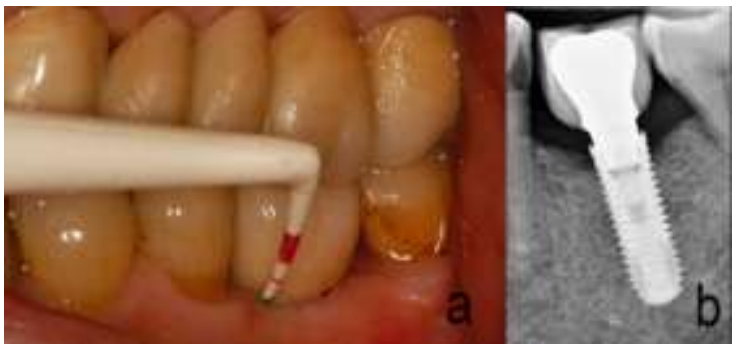

Resim-7: a. Tedavi sonrası 2.yıl ağız içi görünümü b. Tedavi sonrası 2.yıl radyografik görünümü

\section{TARTIŞMA}

Bu vaka raporunun amacı mevcut peri-implant defektinin, otojen kemik grefti ve destekleyici membran olarak serbest bukkal yağ dokusunun kullanılarak tedavi edilmesidir. Sonuç olarak implant etrafında hem yumuşak hem de sert dokuda klinik ve radyografik muayene sonucunda gözle görülebilir iyileşme tatmin ediciydi. Bu teknik, mevcut raporları ${ }^{14,15}$ doğrular şekilde lezyonun rejenerasyonunu sağlamıştır.

Maksillofasiyal cerrahide bukkal yağ greft iyileşmesinin doğası geniş bir şekilde raporlanmış ve ana mekanizmasının fibrözis ve hızlı epitelizasyondan kaynaklı olduğu belirtilmiştir ${ }^{6}$. SBYG'ler farklı verici bölgelerden alınabilir ve vücudun her yerindeki farklı alıcı bölgelere nakledilebilir ${ }^{14}$. Kablan ve Laster $^{13}$ yaptıkları çalışmada, cerrahi sonrası SBYG'nin olgunlaşmamış fibrözisin 1.ayda, olgunlaşmış fibrözisin ise 4.ayda görüldüğünü belirtmişlerdir. SBYG'nin fibroz iyileştirici doğası, ince doku biyotipini kalın biyotipe dönüştürebildiği ve alıcı bölgenin yumuşak doku kalitesini ve hacmini artırdığını tespit etmişlerdir ${ }^{13}$.

Samman ve ark. ${ }^{17}$ yapmış oldukları çalışmada, bukkal yağ dokusunun 4-6 hafta içerisinde fibrotik olarak iyileştiği, sert ve sıkı bir kapama sağladığı, ayrıca postoperatif dönemde 6-8 $\mathrm{mm}$ derinlikten alınan biyopsi kesitlerinin hiçbirinde yağ hücresine rastlanılmadığını rapor etmişlerdir.

Kablan $^{14}, 22$ peri-implant lezyonun 8'inin tedavisinde yeni bir teknik olarak bukkal yağ kütlesinden elde edilen serbest yağ doku greftini kullanmıştır. Tüm hastalarda greft alınan bölgenin problemsiz iyileştiğini, lezyon bölgesinde cerrahiden 12 ay sonra serbest yağ greftinin fibröz iyileşme göstermesi ile sondlamada kanama, cep derinliği ve klinik ataşman seviyesinde tatmin edici kazanımlar elde edildiğini rapor etmiştir ${ }^{14}$. Yazar ayrıca fibrotik dokunun tedavi edilmiş implantın koronal kısmına daha güçlü yapıştığını, olgun fibrözisi histolojik olarak göstermiş ve böylece peri-implant lezyonun nüksünü engellediğini ileri sürmüştür ${ }^{14}$.

Peñarrocha-Diago ve ark. ${ }^{15}, 27$ hastanın posterior maksillasında periodontitis, fraktür ve restoratif nedenlerle çekilip immediyat yerleştirilen implantların bukkal yüzeyindeki defekt bölgesine kemik greft materyali ve bariyer membran olarak bukkal yağ dokusu uygulamışlardır. Yazarlar, 12 aylık takip sonunda periimplant kemik defekt bölgesinde kemik greft materyalinin örtülmesi için bukkal yağ dokunun kullanımının, hastalar tarafından iyi tolere edildiğini ve yüksek implant başarı oranı kazanıldığını belirtmişlerdir ${ }^{15}$.

$\mathrm{Bu}$ olgu raporunda, bukkal yağ dokusu periimplant defekte yerleştirilen otojen kemik greft materyalini yapısını, organizasyonunu ve iyileşmesini desteklemiştir. Hastanın cerrahi sonrası kısa ve uzun süreli takiplerinde bu uygulamayı iyi tolere ettiği (ağrı, inflamasyon vb.) belirlenmiştir. Kablan ${ }^{14}$ ve Peñarrocha- Diago ve ark. ${ }^{15}$ 'nın yapmış oldukları çalışmalarındaki veriler, bu vaka raporunun verileri ile uygunluk göstermektedir ve çalışmaların sonuçlarını doğrular nitelikte bulgular vermiştir.

\section{SONUÇ}

$\mathrm{Bu}$ olgu raporunda, bariyer membran olarak kullanılan serbest bukkal yağ dokusu kemik greft partiküllerini koruyarak yumuşak dokuya kolayca adapte olmuştur. Ancak, SBYG'nin peri-implant defektlerin tedavisi için kullanımının uzun dönem güvenilirliği için ek takipler ve çalışmalar gereklidir.

NOT: Calışmada herhangi bir yazar, kurum ya da kuruluş ile çıkar çatışması içerisinde bulunmamaktadır. Makale daha önce hiçbir yerde yayınlanmamış ve yayınlanmak üzere işlem görmemektedir 


\section{KAYNAKLAR}

1. Misch CE. Günümüz Diş Hekimliğinde İmplantoloji (Türkçe Çeviri Editörü: Tulunoğlu İF). 3.Baskı. Ankara:2011. p. 72-3.

2. Renvert S, Polyzois I. Treatment of pathologic periimplant pockets. Periodontol 2000 2018;76:18090.

3. Karaaslan F, Terzi M. Association between periimplant diseases and cement-retained prosthesis: A review. J Dent Fac Atatürk Uni 2016;16:80-84

4. Tostevin PMJ, Ellis $H$. The buccal pad of fat: A review. Clinical Anatomy 1995;8:403-6.

5. Stuzin JM, Wagstrom L, Kawamoto HK, Baker TJ, Wolfe SA. The anatomy and clinical applications of the buccal fat pad. Plastic and Reconstructive Surgery 1990;85:29-37.

6. Bradley P. Buccal pad of fat and its applications in oral and maxillofacial surgery: a review of published literature (February) 2004 to (July) 2009. Oral Surg Oral Med Oral Pathol Oral Radiol Endod 2011;112:46.

7. Abad-Gallegos $M$, Figueiredo $R$, Rodríguez-Baeza A, Gay- Escoda C. Use of Bichat's buccal fat pad for the sealing of orosinusal communications. A presentation of 8 cases. Med Oral Patol Oral Cir Bucal 2011;16:e215-9.

8. Nezafati S, Vafaii A, Ghojazadeh M. Comparison of pedicled buccal fat pad flap with buccal flap for closure of oro-antral communication. Int J Oral Maxillofac Surg 2012;41:624-8.

9. Ferrari S, Ferri A, Bianchi B, Copelli C, Magri AS, Sesenna E. A novel technique for cheek mucosa defect reconstruction using a pedicled buccal fat pad and buccinator myomucosal island flap. Oral Oncol 2009;45:59-62.

10. Alkan A, Dolanmaz D, Uzun E, Erdem E. The reconstruction of oral defects with buccal fat pad. Swiss Med Wkly 2003;133:465-70.

11. Riu GD, Meloni SM, Bozzo C, Meloni F, Tullio A. A double buccal fat pad flap for middle palate defect closure-a new technique for palate closure. Int J Oral Maxillofac Surg 2006;35:1057-9.

12. Hassani A, Khojasteh A, Alikhasi M. Repair of the perforated sinus membrane with buccal fat pad during sinus augmentation. J Oral Implantol 2008;34:330-3.

13. Kablan F, Laster Z. The use of free fat tissue transfer from the buccal fat pad to obtain and maintain primary closure and to improve soft tissue thickness at bone-augmented sites: Technique presentation and report of case series. Int J Oral Maxillofac Implants 2014;29:e220-31.

14. Kablan F. The use of Buccal fat pad free graft in regenerative treatment of peri-implantitis: A new and predictable technique. Ann Maxillofac Surg 2015;5:179-84

15. Peñarrocha-Diago $M$, Alonso-González $R$, AloyPrósper A, Peñarrocha-Oltra $D$, Camacho $F$, Peñarrocha-Diago $M$. Use of buccal fat pad to repair post-extraction peri-implant bone defects in the posterior maxilla. A preliminary prospective study. Med Oral Patol Oral Cir Bucal 2015;1:e699706.

16. Renvert S, Giovannoli JL. Peri-implantitis. (Türkçe Çeviri Editörü: Soytürk AS). 1.Baskı. İstanbul: 2016. p.150.

17. Samman N, Cheung LK, Tideman H. The buccal fat pad in oral reconstruction. Int $\mathrm{J}$ Oral Maxillofac Surg 1993;22:2-6.

\section{Yazışma Adresi}

Doç. Dr. Figen Öngöz DEDE

Ordu Üniversitesi, Diş Hekimliği Fakültesi, Periodontoloji A.D., Altınordu, ORDU, TÜRKİYE (Sorumlu yazar)

Tel: +90 (0452) 21212 83\7145;

Faks: +90 45221212 89;

E-posta: figen ongoz@hotmail.com 